\title{
UJI TITIK NYALA DAN TITIK BAKAR SEMARBUT ASPAL TIPE 4 BERDASARKAN SNI 2433:2011
}

\author{
Galeh Nur Indriatno Putra Pratama dan Arif Muhammad Yusuf \\ Jurusan Pendidikan Teknik Sipil dan Perencanaan, Fakultas Teknik, Universitas Negeri Yogyakarta \\ Email: galeh@uny.ac.id
}

\begin{abstract}
Asphalt is a filtering material of crude oil used as a pavement material. Asphalt quality becomes a very important and must be considered for pavement material, especially in its nature that can be burning and burning. Flash point and asphalt burn point is very important to know as planning of pavement material so that at certain condition of asphalt does not burn. This test aims to determine the point of flame and asphalt burn point. The asphalt samples were taken from asphalt inventory in the laboratory of pavement material of Department of Civil Engineering Education and Planning of FT UNY. The method used is to compare the result of flash point test and burn the emulsion asbuton extract using a modified solar refinery with penetration asphalt 60/70 (asphalt semarbut type 4) with flame point test and asphalt burn 60/70 regular penetration without modification with cleveland cup with regulation of SNI 2433: 2011. Data processing and graphics program used MS Exel 2010 application. Based on the test results concluded that the testing point and point of burning asphalt has been done obtained average flame point value at $250^{\circ} \mathrm{C}$ in an average time of 1.193 minutes, while the value of fuel point occurs when the asphalt temperature is $280^{\circ} \mathrm{C}$ in an average time of 3.48 minutes.
\end{abstract}

Keywords: asphalt, flash point, fuel point

\begin{abstract}
ABSTRAK
Aspal merupakan material hasil penyaringan minyak mentah yang digunakan sebagai bahan perkerasan jalan. Kualitas aspal menjadi suatu yang sangat penting dan harus diperhatikan untuk bahan perkerasan, terutama dalam sifatnya yang bisa menyala dan terbakar. Titik nyala dan titik bakar aspal sangat penting diketahui sebagai perencanaan bahan perkerasan jalan agar pada saat kondisi tertentu aspal tidak terbakar. Pengujian ini bertujuan untuk mengetahui titik nyala dan titik bakar aspal. Sampel aspal diambil dari aspal persediaan di laboratorium bahan perkerasan jalan Jurusan Pendidikan Teknik Sipil dan Perencanaan FT UNY. Metode yang digunakan adalah membandingkan hasil pengujian titik nyala dan bakar ekstrak asbuton emulsi menggunakan peremaja solar yang dimodifikasi dengan aspal penetrasi 60/70 (semarbut aspal tipe 4) dengan pengujian titik nyala dan bakar aspal penetrasi 60/70 biasa tanpa modifikasi dengan alat cleveland cup sesuai dengan peraturan SNI 2433:2011. Pengolahan data dan grafik digunakan program aplikasi MS Exel 2010. Berdasar hasil pengujian disimpulkan bahwa pada pengujian titik nyala dan titik bakar aspal yang telah dilakukan diperoleh rata-rata nilai titik nyala pada suhu $250^{\circ} \mathrm{C}$ dalam waktu rata rata 1,193 menit, sedangkan nilai titik bakar terjadi ketika suhu aspal $280^{\circ} \mathrm{C}$ dalam waktu rata rata 3,48 menit.
\end{abstract}

Kata kunci: aspal, titik nyala, titik bakar 


\section{PENDAHULUAN}

Aspal adalah material hasil penyaringan minyak mentah dan merupakan hasil dari industri perminyakan. Aspal merupakan material untuk perekat, yang berwarna coklat gelap hingga hitam, dengan unsur pokok yang dominan adalah bitumen. Dalam SNI 03-1737-1989, aspal keras didefinisikan sebagai suatu jenis aspal minyak yang merupakan residu hasil destilasi minyak bumi pada keadaan hampa udara, yang pada suhu normal dan tekanan atmosfir berbentuk padat, sedang aspal cair adalah aspal minyak yang pada suhu normal dan tekanan atmosfir berbentuk cair. Aspal ini terdiri dari aspal keras yang diencerkan dengan bahan pelarut (Christady, 2010:143).

Pengujian titik nyala dan titik bakar aspal berguna untuk mengetahui temperatur di mana aspal mulai menyala, dan temperatur dimana aspal mulai terbakar. Data ini dibutuhkan sebagai informasi penting dalam proses pencampuran demi keselamatan dalam bekerja. Pengujian dilakukan dengan mencetak contoh semen aspal di dalam cawan cleveland yang terbuat dari kuningan. Cawan diletakkan di atas pelat pemanas dan dimasukkan termometer pengukur temperatur. Temperatur di mana aspal terlihat menyala singkat merupakan temperatur titik nyala, dan temperatur dimana aspal mulai menyala selama minimal 5 detik dinamakan titik bakar (Sukirman, 2003:42).

Aspal memiliki titik nyala dan titik bakar pada suhu tertentu. Menurut SNI 06-24331991 halaman 1, titik nyala adalah suhu pada saat terlihat nyala singkat kurang dari 5 detik pada suatu titik di atas permukaan aspal, sedangkan titik bakar adalah suhu pada saat terlihat nyala sekurangkurangnya 5 detik pada suatu titik pada permukaan aspal.

Hasil dari pengujian titik nyala dan titik bakar ini, dibandingkan dengan penelitian Djoko Sarwono, dkk. yaitu karakteristik ekstrak asbuton emulsi menggunakan peremaja solar yang dimodifikasi dengan aspal penetrasi 60/70 (semarbut aspal tipe 4).

Djoko Sarwono, dkk (2018), berpendapat semarbut aspal tipe 1 adalah penelitian tentang modifikasi aspal penetrasi 60/70 dengan ekstrak asbuton menggunakan bahan peremaja kerosin yang dilakukan oleh Sadu Januar (2014). kadar optimum ekstrak asbuton pada Semarbut Aspal Tipe 1 adalah 27,5\%, akan tetapi hasil uji penetrasi terlalu tinggi sehingga aspal yang dihasilkan sangat lembek. Semarbut Aspal Tipe 2 adalah penelitian tentang modifikasi aspal penetrasi 60/70 dengan ekstrak asbuton menggunakan bahan peremaja premium yang dilakukan oleh Luqman Try (2016) dan menghasilkan kadar optimum ekstrak asbuton pada semarbut sebesar $42,5 \%$.

Hasil kajian Djoko Sarwono, dkk (2018) merupakan lanjutan dari penelitian semarbut yang menggunakan solar sebagai bahan peremaja saat proses pembuatan ekstrak asbuton emulsi. Pemilihan bahan peremaja solar karena solar memiliki nilai viskositas yang tinggi dan merupakan salah satu jenis minyak berat, sehingga dengan menggunakan bahan peremaja solar diharapkan aspal yang dihasilkan tidak getas. Selanjutnya ekstrak asbuton dimodifikasi menggunakan aspal penetrasi 60/70 menjadi Semarbut Aspal Tipe 4. Modifikasi aspal pada penelitian ini bertujuan menghasilkan kadar optimum ekstrak asbuton pada komposisi semarbut yang lebih besar sehingga dapat mengurangi penggunaan aspal minyak.

Studi kasus pengujian titik nyala dan bakar ini, dilaksanakan dengan bahan aspal yang sama yaitu: aspal dengan penetrasi 60/70 dengan perbedaan pada penelitian Djoko Sarwono, dkk menggunakan peremaja solar dan menggunakan ekstrak asbuton emulsi.

Standar Nasional Indonesia (SNI) tentang cara uji titik nyala dan titik bakar aspal dengan alat cleveland open cup adalah revisi dari SNI 06-2433-1991, Metode 
pengujian titik nyala dan titik bakar bahan aspal dengan Cleveland open cup dan merupakan adopsi identik dari ASTM D 9202b Standard Test Method for Flash and Fire Points by Cleveland Open Cup Tester. Cara uji titik nyala dan titik bakar aspal dengan alat cleveland open cup ini dimaksudkan sebagai acuan dan pegangan teknisi laboratorium, produsen aspal agar diperoleh keseragaman cara uji (SNI 2433-2011:ii).

Titik nyala dapat digunakan untuk mengukur kecenderungan aspal dapat

\section{METODE}

Titik nyala dan bakar aspal dapat digunakan untuk mengukur kecenderungan aspal dapat terbakar panas dan api pada kondisi terkontrol di laboratorium. Hasil tersebut dapat digunakan sebagai informasi bahaya kebakaran yang sesungguhnya di lapangan.

Metode yang digunakan adalah membandingkan pengujian titik nyala di laboratorium (aspal tanpa campuran apapun murni aspal pen 60/70) dengan hasil penelitian Djoko Sarwono,dkk yang menguji karakteristik asbuton emulsi menggunakan peremaja solar yang dimodifikasi dengan aspal penetrasi 60/70 (semarbut tipe 4). terbakar akibat panas dan api pada kondisi terkontrol di laboratorium. Hasil tersebut dapat digunakan sebagai informasi bahaya kebakaran yang sesungguhnya di lapangan. Peralatan yang digunakan terdiri dari: cawan cleveland, pelat pemanas, nyala api penguji, termometer, pemanas dan penyangga, sedangkan bahan yang digunakan adalah pelarut pembersih yang terdiri dari aseton, toluen, xylene dan minyak tanah (SNI 2433-2011:iii).

Semarbut aspal adalah aspal yang dimodifikasi dengan hasil ekstraksi asbuton. Semarbut merupakan kepanjangan dari sebelas maret (semar) asbuton, karena penelitiannya dilakukan di Universitas Sebelas Maret Surakarta (Djoko Sarwono, dkk: 2018).

Penelitian Djoko Sarwono, dkk Pembuatan Semarbut Aspal Tipe 4 digunakan metode pencampuran panas-panas, yaitu memanaskan aspal penetrasi 60/70 hingga $100^{\circ} \mathrm{C}$ terlebih dahulu kemudian dicampur dengan ekstrak asbuton yang sudah dipanaskan sehingga kandungan air didalamnya hilang. Pada tahap ini dilakukan beberapa variasi komposisi antara kadar asbuton emulsi dan kadar aspal penetrasi 60/70 yang dapat dilihat pada Tabel 1

Tabel 1. Variasi komposisi Semarbut Aspal Tipe 4

\begin{tabular}{ccc}
\hline No & $\begin{array}{c}\text { Kadar ekstrak asbuton } \\
(\%)\end{array}$ & $\begin{array}{c}\text { Kadar aspal penetrasi } 60 / 70 \\
(\%)\end{array}$ \\
\hline 1 & 35,0 & 65,0 \\
\hline 2 & 37,5 & 62,5 \\
\hline 3 & 40,0 & 60,0 \\
\hline 4 & 42,5 & 57,5 \\
\hline 5 & 45,0 & 55,0 \\
\hline
\end{tabular}

Pengujian karakteristik aspal melingkupi: pengujian penetrasi, pengujian titik lembek aspal, pengujian titik nyala dan bakar aspal, dan pengujian marshaal. Dalam studi kasus ini dibatasi tentang pengujian titik nyala dan titik bakar aspal dengan digunakan cara uji titik nyala dan titik bakar aspal dengan alat cleveland open cup adalah revisi dari SNI
06-2433-1991. Peralatan yang digunakan terdiri dari: cawan cleveland, pelat pemanas, nyala api penguji, termometer, pemanas dan penyangga. Sedangkan bahan yang digunakan adalah aspal,dan pelarut pembersih yang terdiri dari aseton, toluen, xylene dan minyak tanah. 
Studi Kasus Pengujian... (Galeh/ hal 62-73)

Dalam pengujian titik nyala dan titik bakar aspal, langkah kerjanya adalah sebagai berikut:

1. Alat dan bahan yang dibutuhkan dipersiapkan.
2. Aspal dimasukkan ke dalam cleveland open cup sampai batas yang terdapat pada cleveland open cup.

3. Cleveland open cup diletakkan di atas kompor.

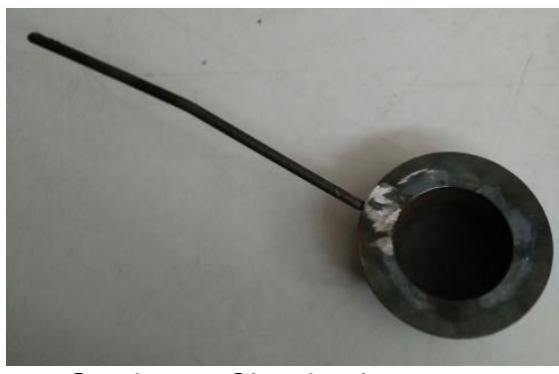

Gambar 1. Cleveland open cup

4. Termometer dipasang sedemikian rupa sehingga dapat mengukur suhu aspal dengan baik. Kira-kira dipasang pada seperempat diameter cawan cleveland open cup.
5. Suhu awal aspal diukur sebelum dipanaskan.

6. Kompor listrik dinyalakan untuk memanaskan aspal.

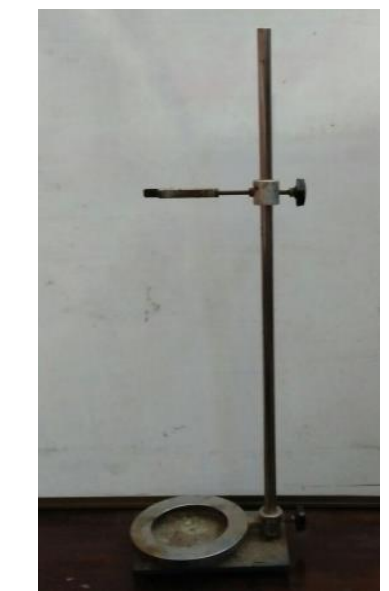

Gambar 2. Penjepit termometer

7. Suhu aspal diamati ketika dipanaskan dan mencatat waktunya setiap kenaikan suhu $5^{\circ} \mathrm{C}$.

8. Api dan minyak tanah disiapkan untuk menyalakan tongkat sumbu yang akan digunakan untuk menguji titik nyala dan titik bakar aspal.
9. Ketika suhu aspal telah mencapai kirakira $200^{\circ} \mathrm{C}$, maka aspal sudah dapat diuji titik nyala maupun titik bakarnya.

10. Api dinyalakan pada tongkat sumbu dan menguji titik nyala aspal dengan cara api tersebut dilewatkan pada sisi atas aspal dengan jarak $\pm 1 \mathrm{~cm}$ dari permukaan atas aspal 


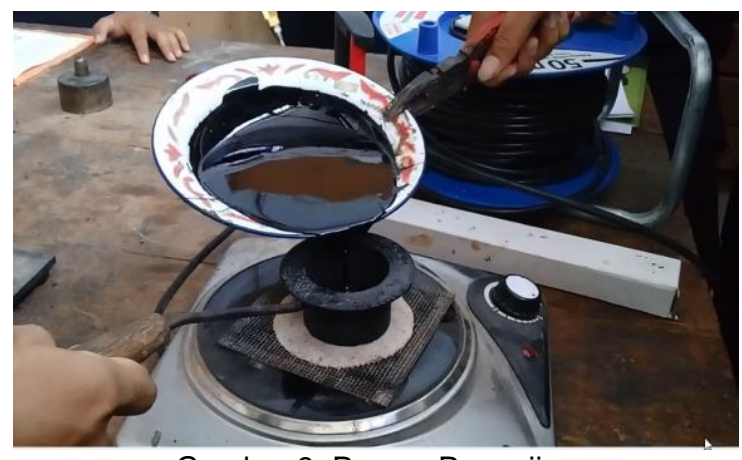

Gambar 3. Proses Pengujian

11. Apabila masih belum terdapat percikan api, maka langkah 10 dilakukan berulang-ulang sampai terdapat percikan api pada aspal ketika api dilewatkan di atas aspal dengan tetap mengamati kenaikan suhu dan mencatat waktu setiap kenaikan suhu aspal sebesar $5^{\circ} \mathrm{C}$.

12. Setelah langkah 10 terus diulangi dan timbul percikan api pada permukaan atas aspal, maka pada saat itulah titik nyala aspal.

13. Kemudian suhu yang terukur pada termometer ketika titik nyala aspal telah tercapai dan waktu yang dibutuhkan dicatat.

14. Setelah itu, aspal masih terus dipanaskan dan suhu aspal masih terus diamati dengan mencatat waktu setiap kenaikan $5^{\circ} \mathrm{C}$.

15. Ketika titik nyala aspal telah tercapai, maka aspal harus sering diuji dengan cara api dilewatkan di atas aspal dengan cara serupa pada langkah 10.

16. Setelah terdapat nyala api pada permukaan aspal selama \pm 5 detik, maka saat itulah titik bakar aspal telah tercapai.

Kemudian suhu yang tertera pada termometer diamati dan waktu yang dibutuhkan dicatat ketika titik bakar aspal telah tercapai.

\section{HASIL DAN PEMBAHASAN}

Pengujian titik nyala dan titik bakar aspal yang kami lakukan, dilaksanakan di Laboratorium Bahan Perkerasan Jalan Jurusan Pendidikan Teknik Sipil dan Perencanaan Universitas Negeri
Yogyakarta. Pengujian dilaksanakan pada April 2018. Adapun data hasil percobaan ditampilkan seperti dalam tabel di bawah ini:

Tabel 2. Hasil Percobaan 1

\begin{tabular}{ccccc}
\hline \multirow{2}{*}{ No. } & $\begin{array}{c}\text { Suhu } \\
\left({ }^{\circ} \mathrm{C}\right)\end{array}$ & Waktu & Waktu & \\
\cline { 3 - 4 } & & tercatat & (menit) & \\
\hline 1 & 250 & $0: 00: 00$ & 0,00 & suhu awal \\
2 & 260 & $0: 01: 00$ & 1,00 & suhu 1 menit \\
3 & 265 & $0: 01: 12$ & 1,20 & suhu nyala \\
4 & 280 & $0: 02: 48$ & 2,80 & suhu bakar \\
\hline
\end{tabular}


Tabel 3. Hasil Percobaan 2

\begin{tabular}{ccccc}
\hline \multirow{2}{*}{ No. } & $\begin{array}{c}\text { Suhu } \\
\left({ }^{\circ} \mathrm{C}\right)\end{array}$ & Waktu & Waktu & Keterangan \\
\cline { 3 - 4 } & 240 & 0:00:00 & 0,00 & suhu awal \\
\hline 1 & 240 menit) & \\
2 & 245 & $0: 01: 00$ & 1,00 & suhu 1 menit \\
3 & 250 & $0: 01: 44$ & 1,73 & suhu nyala \\
4 & 255 & $0: 02: 00$ & 2,00 & suhu 2 menit \\
5 & 270 & $0: 03: 00$ & 3,00 & suhu 3 menit \\
6 & 280 & $0: 03: 49$ & 3,82 & suhu bakar \\
\hline
\end{tabular}

Tabel 4. Hasil Percobaan 3

\begin{tabular}{|c|c|c|c|c|}
\hline \multirow{2}{*}{ No. } & \multirow{2}{*}{$\begin{array}{l}\text { Suhu } \\
\left({ }^{\circ} \mathrm{C}\right)\end{array}$} & \multirow{2}{*}{$\frac{\text { Waktu }}{\text { tercatat }}$} & \multirow{2}{*}{$\frac{\text { Waktu }}{\text { (menit) }}$} & \multirow{2}{*}{ Keterangan } \\
\hline & & & & \\
\hline 1 & 230 & 0:00:00 & 0,00 & suhu awal \\
\hline 2 & 235 & $0: 00: 38$ & 0,63 & suhu nyala \\
\hline 3 & 240 & 0:01:00 & 1,00 & suhu 1 menit \\
\hline 4 & 255 & $0: 02: 00$ & 2,00 & suhu 2 menit \\
\hline 5 & 270 & 0:03:00 & 3,00 & suhu 3 menit \\
\hline 6 & 280 & $0: 03: 49$ & 3,82 & suhu bakar \\
\hline
\end{tabular}

Tabel 2,3, dan 4 adalah menunjukkan titik nyala dan bakar aspal murni tanpa campuran apapun.

SNI 2433-2011 dapat dijelaskan bahwa titik nyala adalah temperatur terendah dimana uap benda uji dapat menyala (nyala biru singkat) apabila dilewatkan api penguji. Temperatur titik nyala tersebut harus dikoreksi pada tekanan barometer udara $101,3 \mathrm{kPa}(760 \mathrm{~mm} \mathrm{Hg}$ ). Suhu titik nyala aspal terlihat kurang dari 5 detik pada suatu titik di atas permukaan aspal. Titik bakar adalah temperatur terendah ketika uap benda uji terbakar selama minimum 5 detik apabila dilewatkan api penguji. Temperatur titik bakar tersebut harus dikoreksi pada tekanan barometer udara $101,3 \mathrm{kPa}$ (760 $\mathrm{mm} \mathrm{Hg}$ ). Suhu titik bakar aspal pada saat terlihat nyala sekurang-kurangnya 5 detik pada suatu titik permukaan aspal. Dalam menggunakan termometer harus hati-hati, lebih aman menggunakan termometer dengan suhu yang tinggi, jangan sampai memakai termometer dengan suhu rendah, bisa jadi saat pemakaian termometer pecah.

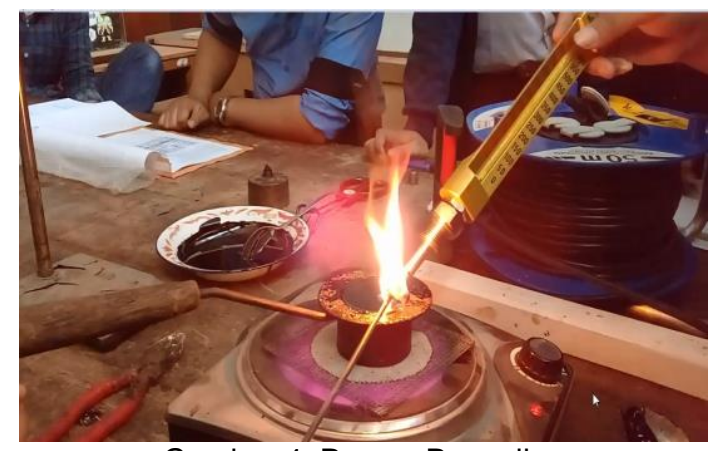

Gambar 4. Proses Pengujian

Pada pengujian titik nyala dan titik bakar yang kami lakukan, kami memulai perhitungan waktu ketika suhu telah mencapai lebih dari $200^{\circ} \mathrm{C}$. Oleh sebab itu kami merencanakan yaitu pada suhu 250 -C pada pengujian pertama, $240^{\circ} \mathrm{C}$ pada pengujian kedua, dan $250^{\circ} \mathrm{C}$ pada pengujian ketiga. Setelah suhu benda uji telah mencapi suhu yang kami rencanakan, maka perhitungan waktu kami mulai. Hal itu dengan tujuan agar dalam pengujian tidak terlalu lama menunggu menggunakan nyala api.

Setelah perhitungan waktu kami mulai, kami mengamati serta mencatat waktu setiap mengalami kenaikan suhu $5^{\circ} \mathrm{C}$. 
Pengujian yang kami laksanakan berada di dalam ruangan yang dibuat tidak terlalu terang sehingga memudahkan kami dalam memperhatikan kapan titik nyala terjadi dan kapan titik bakar terjadi. Untuk mengetahui titik nyala dan titik bakar aspal di pengaruhi oleh ketelitian membaca suhu dan waktu, kesetabilan panas kompor, dan tekanan barometer udara.

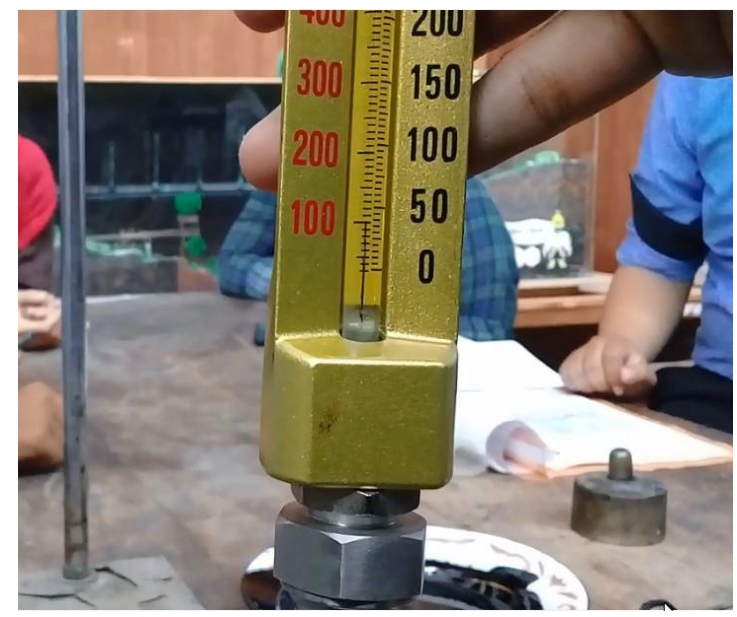

Gambar 5. Pembacaan Termometer

Digunakan termometer dengan kapasitas $1000^{\circ} \mathrm{C}$

Berdasarkan pengujian titik nyala dan titik bakar aspal yang telah kami lakukan, maka diperoleh data berupa daftar waktu yang dibutuhkan untuk mencapai keadaan titik nyala dan titik bakar aspal. Daftar waktu tersebut dapat dilihat pada Tabel 2, Tabel 3 dan Tabel 4. Dalam membaca waktu-waktu tersebut digunakan stopwatch agar waktu dapat detil pada detik dan menitnya.

Dari hasil pengujian titik nyala dan titik bakar tersebut, dapat disajikan dalam bentuk grafik untuk benda uji pengujian titik nyala dan titik bakar, seperti yang tercantum pada gambar 6, gambar 7, dan gambar 8, dari grafik tersebut diperoleh data-data regresi $\left(R^{2}\right)$ adalah rata-rata 0,97 . Hal itu dapat mengidentifikasi bahwa pengujian yang dilaksanakan adalah mendekati benar, karena regresinya mendekati nilai 1 .

Aspal mulai diuji ketika sudah mencapai suhu kira-kira $200^{\circ} \mathrm{C}$. Aspal diuji dengan cara melewatkan api di atas permukaan aspal selama kurang dari 5 detik dengan jarak dari permukaan aspal kira-kira $1 \mathrm{~cm}$. Sesuai dengan pengertian titik nyala menurut SNI 06-2433-1991, yaitu titik nyala adalah suhu pada saat terlihat nyala singkat kurang dari 5 detik pada suatu titik di atas permukaan aspal, maka ketika aspal diuji dengan melewatkan api di atas permukaan aspal dan kemudian muncul percikan api selama sesaat atau kurang dari 5 detik, maka pada saat itulah titik nyala aspal tercapai. Dalam menentukan 5 detik ini, kita harus saksama, karena nyala aspal bisa langsung mati, oleh sebab itu perlu kerjasama untuk menentukan nyala aspal dalam jangka waktu 5 detik saja.

Proses melewatkan api di atas permukaan aspal, perlu diperhatikan jangan sampai nyala api mati, karena akan menyebabkan suhu aspal dapat turun kembali, jadi perlu diusahakan agar nyala api terus berkobar agar hasil yang didapatkan titik nyala dan titik bakar tingkat kevalidannya tinggi.

Dilihat dari ketiga grafik gambar 4,5, dan 6, suhu yang di butuhkan untuk mencapai titik nyala masing masing benda uji berbeda beda. Pada benda uji pertama kita mendapati titik nyala aspal berada pada suhu $265^{\circ} \mathrm{C}$. Sedangkan pada benda uji kedua kita mendapati titik nyala aspal pada suhu $250^{\circ} \mathrm{C}$. Dan pada benda uji ketiga kita mendapati titik nyala aspal pada suhu 235 ${ }^{\circ} \mathrm{C}$. Dari keseluruhan titik nyala setiap benda uji dapat di ambil rata rata titik nyala aspal pada suhu $250 \stackrel{\circ}{\circ}$. Hasil tersebut dapat dikatakan benar karena telah melewati batas SNI yaitu $225^{\circ} \mathrm{C}$. 
Studi Kasus Pengujian... (Galeh/ hal 62-73)

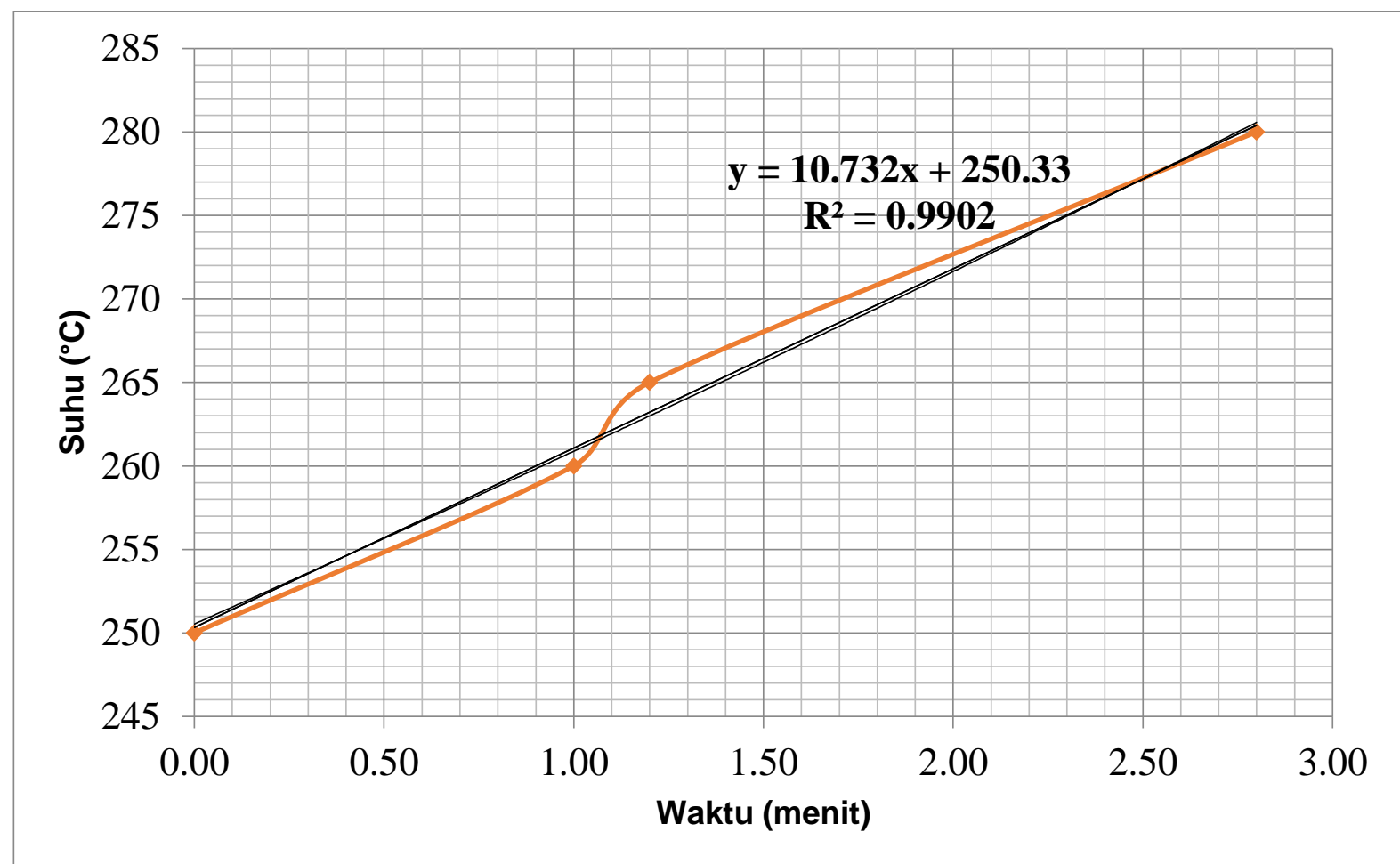

Gambar 6. Grafik perbandingan suhu $\left({ }^{\circ} \mathrm{c}\right)$ terhadap waktu (menit) benda uji pertama

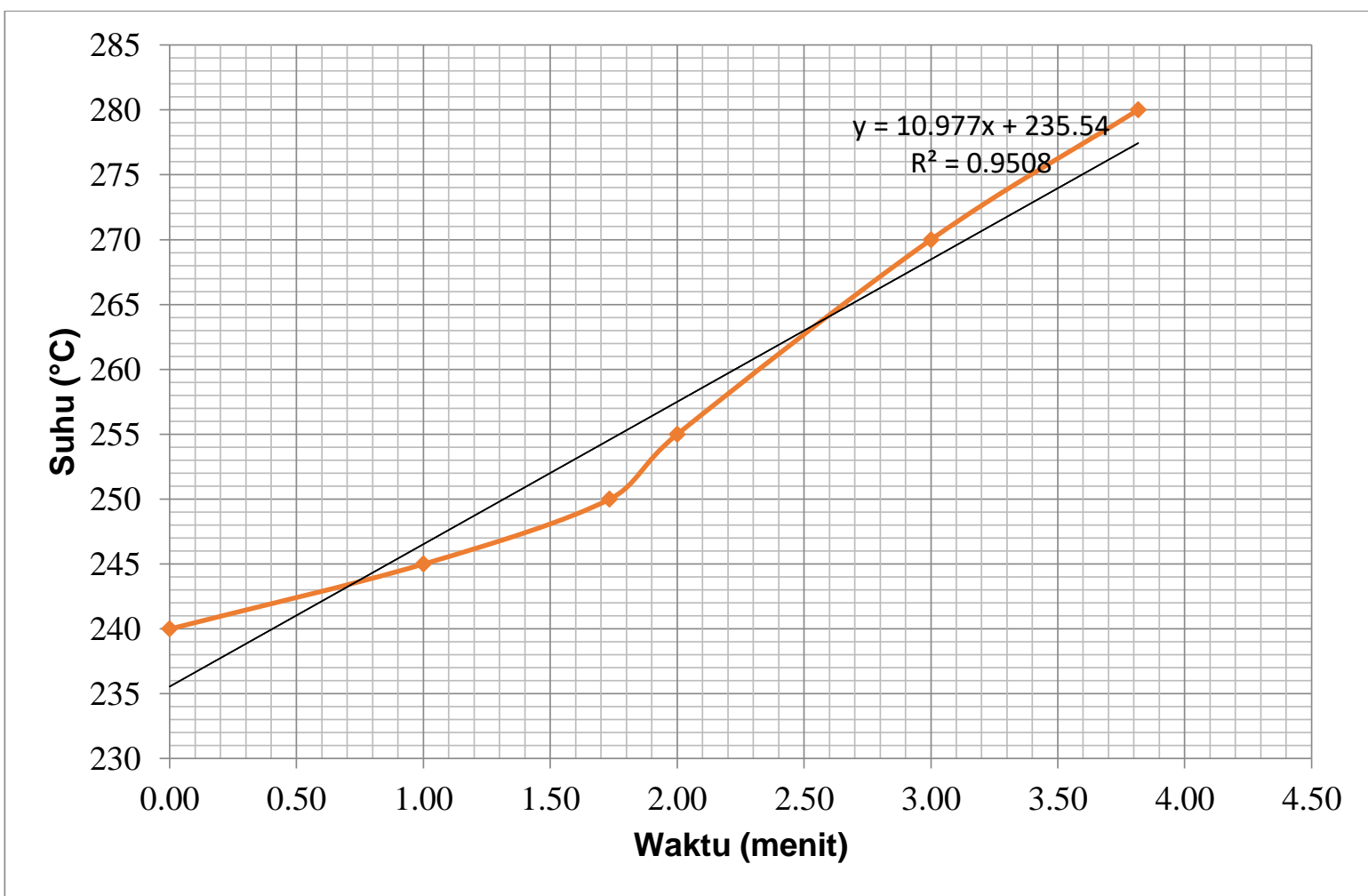

Gambar 7. Grafik perbandingan suhu (ํㅜ) terhadap waktu (menit) benda uji kedua 


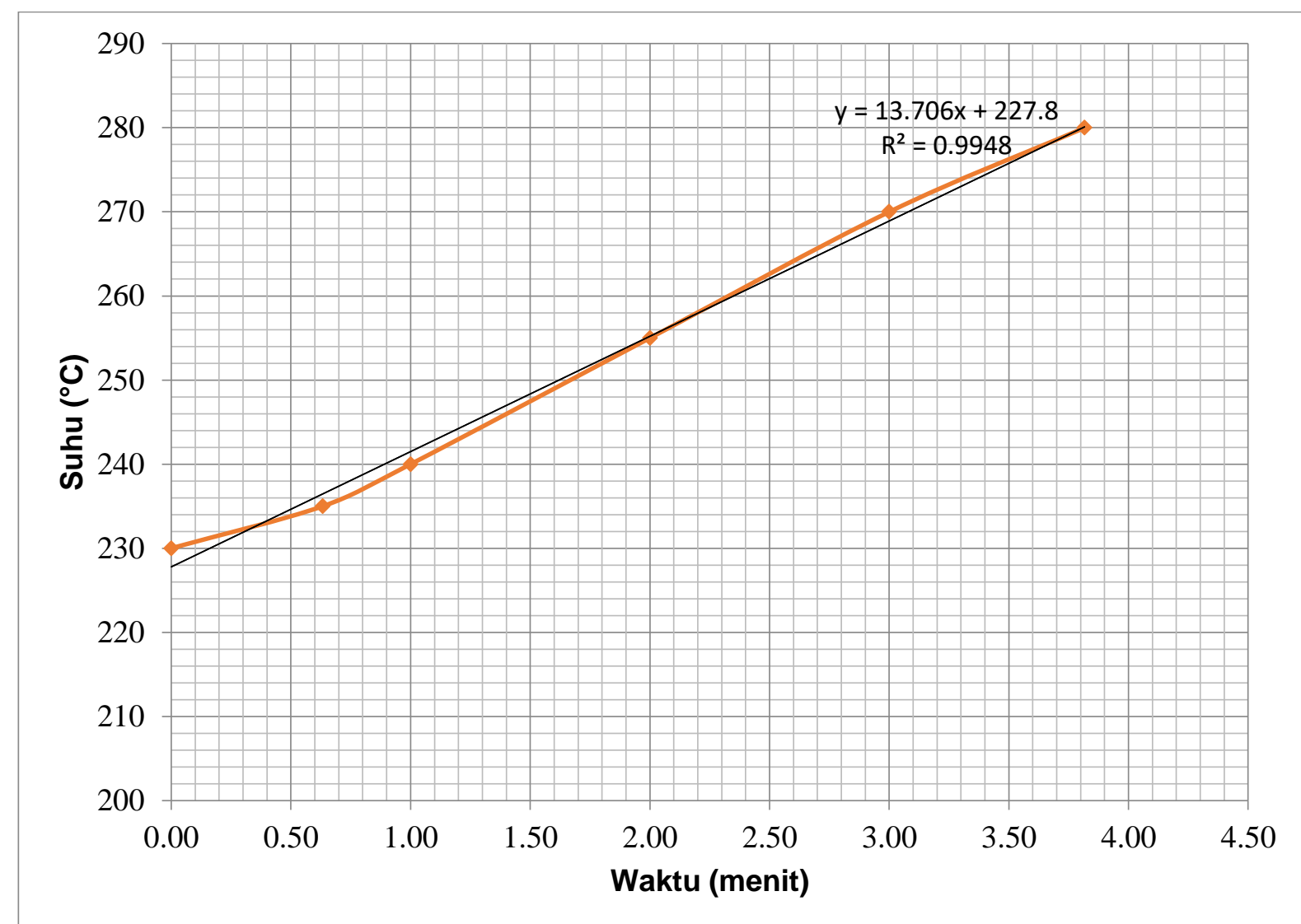

Gambar 8. Grafik perbandingan suhu (ํㅜ) terhadap waktu (menit) benda uji ketiga

Sedangkan titik bakar dari setiap benda uji adalah sama. Dilihat dari grafik di atas benda uji pertama memiliki titik bakar pada suhu $280^{\circ} \mathrm{C}$. Sedangkan benda uji kedua memiliki titik bakar pada suhu $280^{\circ} \mathrm{C}$. dan begitu pula dengan benda uji ke tiga yang memiliki titik bakar pada suhu $280 \stackrel{\circ}{\circ}$.
Berdasarkan data yang didapat, titik nyala terjadi ketika suhu aspal mencapai rata rata suhu $250^{\circ} \mathrm{C}$ degan waktu rata rata 1,193 menit. Untuk titik bakar aspal, terjadi ketika suhu aspal $280^{\circ} \mathrm{C}$ dan dicapai dalam waktu rata rata 3,48 menit, dengan titik nyala dan bakar memenuhi kriteria SNI yaitu $225^{\circ} \mathrm{C}$.

Tabel 5. Hasil Pengujian Karakteristik Semarbut Aspal Tipe 4

\begin{tabular}{|c|c|c|c|c|c|c|c|c|}
\hline \multirow{3}{*}{$\begin{array}{l}\text { Kadar } \\
\text { ekstrak } \\
\text { asbuton } \\
(\%)\end{array}$} & \multirow{3}{*}{$\begin{array}{l}\text { Kadar } \\
\text { aspal pen } \\
60 / 70 \\
(\%)\end{array}$} & \multicolumn{7}{|c|}{ Hasil pengujian karakteristik } \\
\hline & & Penetrasi & $\begin{array}{l}\text { Titik } \\
\text { lembek }\end{array}$ & $\begin{array}{l}\text { Titik } \\
\text { nyala }\end{array}$ & $\begin{array}{l}\text { Titik } \\
\text { bakar }\end{array}$ & Daktilitas & $\begin{array}{l}\text { Berat } \\
\text { jenis }\end{array}$ & Kelekatan \\
\hline & & $\left(\times 10^{-1} \mathrm{~mm}\right)$ & $\left({ }^{\circ} \mathrm{C}\right)$ & $\left({ }^{\circ} \mathrm{C}\right)$ & $\left({ }^{\circ} \mathrm{C}\right)$ & $(\mathrm{cm})$ & (gr/cc) & $(\%)$ \\
\hline 35,0 & 65,0 & 51,6 & 55,75 & 240 & 283 & 59,75 & 1,1980 & 100 \\
\hline 37,5 & 62,5 & 46,7 & 54,75 & 241 & 281 & 57,50 & 1,2113 & 100 \\
\hline 40,0 & 60,0 & 45,7 & 55,50 & 242 & 279 & 54,75 & 1,2304 & 100 \\
\hline 42,5 & 57,5 & 43,1 & 55,75 & 237 & 270 & 48,00 & 1,2350 & 100 \\
\hline 45,0 & 55,0 & 37,7 & 56,50 & 236 & 261 & 47,00 & 1,2421 & 100 \\
\hline
\end{tabular}

Sumber tabel : Penelitian Djoko Sarwono, dkk. 2018.

Dari pengujian tersebut, maka aspal jenis ini dapat dihamparkan pada konstruksi jalan dengan ketentuan jika aspal sudah terhampar dan dipadatkan diusahakan konstruksi tersebut tidak terkena api pada suhu di atas $250^{\circ} \mathrm{C}$. Apabila hal ini terjadi pada kebakaran di daerah lahan gambut, dan suhu tanah di bawah aspal sudah melewati titik nyala aspal, maka hendaknya jalan tersebut tidak diperbolehkan untuk dilewati kendaraan, demi keamanan pengguna jalan. 
Dari pembahasan tersebut dibandingkan dengan Semarbut aspal tipe 4, yang didapatkan hasil pengujian karakteristiknya terdapat pada Tabel 5.

Tabel 5 memberikan informasi data titik nyala dan titik bakar Semarbut tipe 4, semakin besar kadar ekstrak asbutonnya dan semakin kecil kadar aspal dengan jenis aspal penetrasi 60/70, maka titik nyala dan titik bakar semakin kecil. Akan tetapi seharusnya titik nyala dan titik bakar semakin membesar.

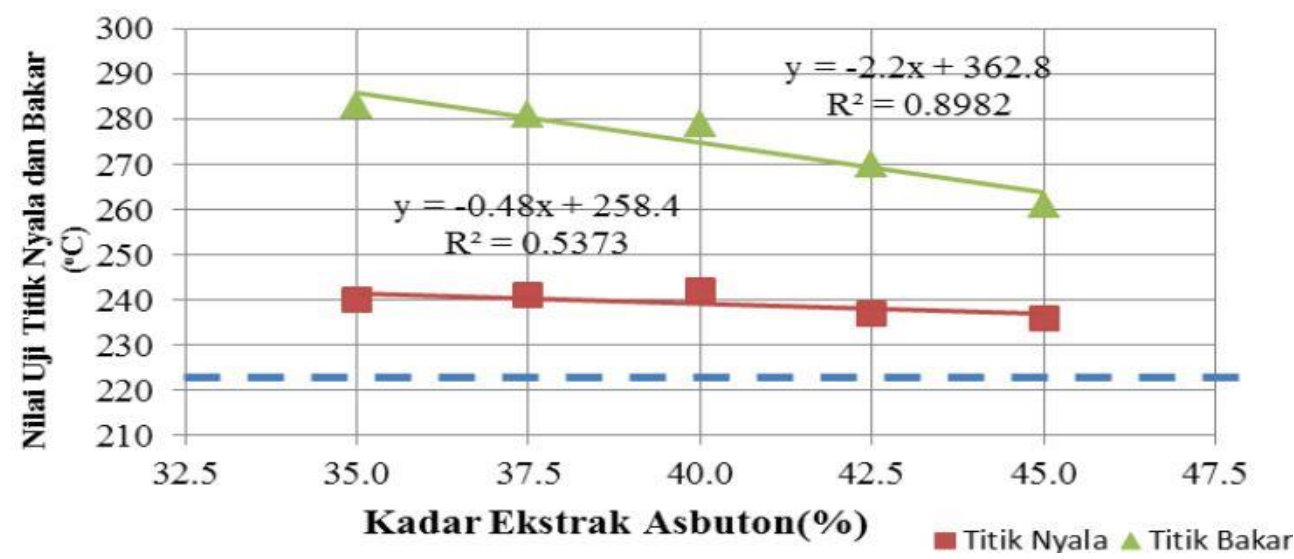

Gambar 9. Grafik perbandingan kadar ekstrak asbuton (\%) terhadap titik nyala dan bakar $\left({ }^{\circ} \mathrm{C}\right)$ (Sumber: Penelitian Semarbut Aspal tipe 4. Djoko Sarwono, dkk. 2018.)

Gambar 9 menunjukkan bahwa semakin banyak kadar ekstrak asbuton yang ditambahkan semakin rendah nilai titik nyala dan titik bakar yang dihasilkan. Suhu titik nyala dan titik bakar dari kelima variasi memenuhi syarat spesifikasi aspal yang dimodifikasi dengan asbuton yaitu suhu minimal $225^{\circ} \mathrm{C}$. Penurunan suhu pada titik nyala dan titik bakar dikarenakan masih adanya kadar solar dalam ekstrak asbuton yang mana proses peremajaanya diperkirakan belum selesai (Djoko Sarwono, dkk, 2018).

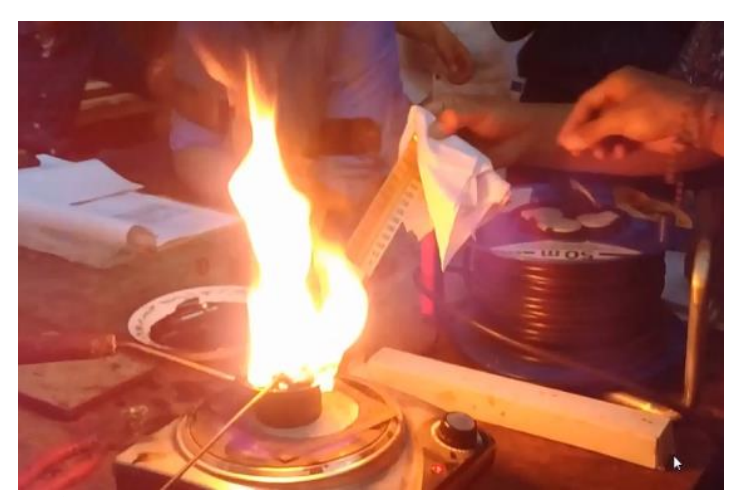

Gambar 10. Pengujian saat tercapai titik nyala

Dari data-data yang ada dan dibandingkan ternyata titik nyala kadar aspal murni $100 \%$ lebih tinggi yaitu $250^{\circ} \mathrm{C}$ dibandingkan titik nyala semarbut tipe 4 yang kadar memiliki kadar estrak asbuton 35-45\% memiliki titik nyala $230-245^{\circ} \mathrm{C}$. Begitu pula titik bakarnya, titik bakar aspal murni $100 \%$ lebih tinggi yaitu $280^{\circ} \mathrm{C}$ dibandingkan titik bakar semarbut tipe 4 yang kadar memiliki kadar estrak asbuton $35-45 \%$ memiliki titik bakar $260-285^{\circ} \mathrm{C}$.

Dilihat dari selisih yang kecil kemungkinan besar jika kadar solar dalam asbuton peremajaannya telah selesai, maka semarbut tipe 4 ini titik nyala dan bakarnya akan sama dengan aspal minyak murni. 
Berdasarkan hasil dari pengujian karakteristik aspal dan kadar kelarutan aspal dapat diketahui bahwa variasi komposisi semarbut dengan kadar ekstrak asbuton sebesar $35 \%$ dan $40 \%$ memenuhi semua spesifikasi nilai karakteristik aspal yang disyaratkan pada aspal yang dimodifikasi oleh asbuton, untuk kadar $37,5 \%$ semua spesifikasi nilai karakteristik aspal memenuhi syarat kecuali nilai titik lembek, sedangkan untuk kadar $42,5 \%$ dan $45 \%$ nilai daktilitas dan penetrasinya tidak memenuhi syarat. Diantara variasi semarbut dengan kadar ekstrak asbuton sebesar $35 \%$ dan $40 \%$ yang memenuhi semua spesifikasi nilai karakteristik aspal, maka dipilih satu komposisi optimum untuk Semarbut Aspal Tipe 4 yaitu kadar ekstrak asbuton sebesar $40 \%$ dan kadar aspal penetrasi $60 / 70$ sebesar $60 \%$, hal ini dikarenakan ekstrak asbuton yang digunakan lebih banyak sehingga pemanfaatan ekstrak asbuton lebih maksimal (Djoko Sarwono, dkk, 2018).

\section{SIMPULAN}

Dari hasil percobaan serta pembahasan pengujian titik nyala dan titik bakar aspal dapat disimpulkan bahwa pada pengujian titik nyala dan titik bakar aspal murni kadar $100 \%$ yang telah dilakukan diperoleh rata rata nilai titik nyala pada suhu $250^{\circ} \mathrm{C}$ dalam waktu rata rata 1,193 menit, sedangkan nilai titik bakar terjadi ketika suhu aspal $280^{\circ} \mathrm{C}$ dalam waktu rata rata 3,48 menit pengujian dimulai ketika suhu aspal adalah $\pm 200^{\circ} \mathrm{C}$ dan diamati perlima menit kenaikan suhunya.

\section{DAFTAR RUJUKAN}

Christady, Hari., (2010). Stabilisasi Tanah untuk Perkerasan Jalan. Gadjah Mada University Press: Yogyakarta.

Ernawati, Enik., (2016). Laporan Praktikum Bahan Perkerasan Jalan "Titik Nyala dan Titik Bakar Aspal". Laporan Praktikum tidak diterbitkan. Fakultas
Pengujian-pengujian titik nyala dan titik bakar di atas, dengan murni aspal ataupun dicampur didapatkan titik nyala dan bakar yang tidak jauh berbeda. Adapun penelitian yang dilakukan Dwi Kartikasari dan Samsul Arif (2018) dengan menambahkan limbah plastik pada aspal (laston) AC-WC (Aspalt Concrete-Wearing Course) didapatkan titik nyala sebesar $277^{\circ} \mathrm{C}$ dan titik bakar $295^{\circ} \mathrm{C}$.

Hal itu berarti penambahan limbah plastik juga dapat menambah titik nyala dan bakarnya, juga sebagai pengolahan limbah plastik yang sangat efisien. Dimana pada saat ini negara Indonesia sedang gencar melakukan pembangunan infrastruktur jalan. Dari kedua inovasi bahan perkerasan jalan tersebut yaitu pemanfaatan ekstrak asbuton dan pemanfaatan limbah plastik, selain menambah nilai uji Marshallnya juga sebagai wujud peduli lingkungan dengan memanfaatkan limbah-limbah yang ada menjadi bahan struktur yang akan lebih murah dan efisien.

Dari pengujian titik nyala dan bakar semarbut tipe 4, didapatkan titik nyala terjadi $230-245^{\circ} \mathrm{C}$. Dan didapatkan titik bakar aspal terjadi pada $260-285^{\circ} \mathrm{C}$. Didapatkan suhu nyala dan bakar kurang dari aspal murni disebabkan karena kadar solar dalam asbuton peremajaannya belum selesai. Jadi dimungkinkan yang terbakar adalah solar bukan aspal dengan penetrasi $60 / 70$ tersebut.

Kartikasari, Dwi., Arif, Samsul., (2018). Penambahan Limbah Plastik Pada Campuran Laston (AC-WC) terhadap Karakteristik Marshall. ISSN 20854218. Halaman 334-338: ITN Malang. 
Pratama, G. N. I. P., \& Sumarjo, H. (2018). Aksesibilitas Tata Letak Elevator Penumpang Gedung Kantor Pusat Layanan Terpadu (KPLT) Fakultas Teknik UNY. INformasi dan Ekspose hasil Riset Teknik Slpil dan Arsitektur, 14(1), 26-35.

Sarwono, Djoko., Suryoto,. Rahmawati, D.P., (2018). Karakteristik Ekstrak Asbuton Emulsi Menggunakan Peremaja Solar yang Dimodifikasi dengan Aspal Penetrasi 60/70 (Semarbut Aspal Tipe 4). E-Jurnal Matriks Teknik Sipil : Universitas Negeri Sebelas Maret Surakarta.

Standar Nasional Indonesia 06-2433-1991.

(1991). Metode pengujian titik nyala dan titik bakar dengan alat cleveland open cup. Badan Standarisasi Nasional Indonesia.

Standar Nasional Indonesia 2433-2011. (2011). Cara uji titik nyala dan titik bakar aspal dengan alat cleveland open cup. Badan Standarisasi Nasional Indonesia.

Sukirman, Silvia., (1999). Perkerasan Lentur Jalan Raya. Nova: Bandung.

Sukirman, Silvia., (2003). Beton Aspal Campuran Panas. Granit: Jakarta. 